\title{
SHORT REPORT \\ Did exposure to a severe outbreak of pandemic influenza in 1918 impact on long-term survival?
}

\author{
N. WILSON ${ }^{1} *$ M. BOYD ${ }^{2}$, S. NISA ${ }^{3}$, C. CLEMENT ${ }^{4}$ AND M. G. BAKER ${ }^{1}$ \\ ${ }^{1}$ Department of Public Health, University of Otago, Wellington, New Zealand \\ 2 Adapt Research, Wellington, New Zealand \\ ${ }^{3}$ Institute of Veterinary, Animal and Biomedical Sciences, Massey University, Palmerston North, New Zealand \\ ${ }^{4}$ Te Puke, Bay of Plenty, New Zealand
}

Received 19 February 2016; Final revision 19 June 2016; Accepted 29 June 2016;

first published online 1 August 2016

\section{SUMMARY}

There is some suggestion that infection with pandemic influenza may increase long-term mortality risks. Therefore we aimed to determine if exposure to a severe outbreak of pandemic influenza on a troopship in 1918 impacted on lifespan in the survivors. The troopship with the outbreak cohort had 1107 personnel and the comparison cohort was from two contemporaneous troopships (1108 randomly selected personnel). Data were collected from online individual military files. The main finding was that there was no statistically significant difference in the lifespan of the outbreak cohort and the comparison cohort (means of 71.5 and 71.0 years, respectively). Indeed, the outbreak cohort was actually more likely to survive into the period from 1950 onwards $(P=0.036)$ and to participate in the Second World War $(P=0.043)$. There were no significant differences between the cohorts in terms of occupational class, but the comparison cohort had a higher proportion of rural occupations $(33.3 \% v s .27 \cdot 0 \%, P<0.001)$ and was very slightly older in mid-1918 (27.8 vs. $27 \cdot 2$ years, $P=0 \cdot 028)$. In conclusion, this study found no support for the hypothesis that exposure to the 1918 influenza pandemic adversely impacted on the lifespan in the survivors, at least in this male and military-age population.

Key words: Influenza, pandemic, public health emerging infections.

There are some suggestions in the literature of past pandemic influenza infection being associated with increased long-term mortality rates. A Norwegian study found significantly higher all-cause mortality at middle and old ages of 1918 pandemic influenza survivors who were born between 1895 and 1910 compared to age cohorts born before or after this period [1]. Others have suggested that survivors of 1918 pandemic influenza were primed for late coronary heart

\footnotetext{
* Author for correspondence: Professor N. Wilson, University of Otago, Wellington, Mein St, Newtown, Wellington, New Zealand. (Email: nick.wilson@otago.ac.nz)
}

disease (CHD) mortality (contributing to the rise in CHD in the 1920-1967 period), while the demise of this cohort may then have contributed to the subsequent decline (1968-1985) in CHD mortality in the United States [2].

More specifically, there is evidence for neurological sequelae of infection with pandemic influenza, some of which may be permanent. One review for the 2009 influenza pandemic reported evidence of the occurrence of Guillain-Barré syndrome (GBS), polyneuropathy, and seizures in the infected population [3]. An association between the neurological condition 'encephalitis lethargica' and the influenza pandemic strain of 1918/1919 has also been debated, but recent 
work involving archived human brain specimens may favour other pathogens as being more likely causes [4].

Given this background, we hypothesized that survivors of a severe outbreak of pandemic influenza in 1918 would experience poorer long-term survival compared to that of a comparison group which were not so exposed. To test this hypothesis, we aimed to make use of a natural experiment whereby a particular group of military personnel on a troopship were exposed to a particularly severe outbreak of pandemic influenza in 1918, while those on contemporaneous other troopships were at lower risk of severe infection. That is, in this troopship outbreak nearly all those on the troopship were reported having symptomatic illness with 77 men dying [5]. The latter resulted in a very high mortality rate from pandemic influenza compared to the rest of the New Zealand military during the whole 1918-1919 pandemic period [6]. Indeed, it seems likely that the confined nature of the troopship increased both the risk of infection and also the severity of infection with high case-fatality rates resulting (possibly due to the higher levels of inoculum in the crowded conditions). In contrast, a probably lower (but not precisely known), proportion of the comparison cohort were also infected with pandemic influenza in the late 1918 and 1919 period. But such infections in the comparison group would almost certainly have been in less crowded circumstances than on a troopship (e.g. training camps in England or back in New Zealand).

The outbreak cohort in our study was comprised of all $(n=1107)$ of the male military personnel on the troopship Tahiti [His Majesty's NZ Transport (HMNZT) 107]. Data on 10 women military personnel (all nurses) were not included in the analysis.

The comparison cohort was comprised of an equivalent number of male military personnel who were randomly selected from the troopships that either directly preceded or directly followed the Tahiti's departure from New Zealand on 10 July 1918. These were the Athenic (HMNZT 106) which departed on 13 June 1918 with 793 military personnel and the Ulimaroa (HMNZT 108) which departed on 27 July 1918 with 1010 military personnel. Neither of these vessels had disease outbreaks, and, as with the personnel on the Tahiti, none of these personnel were involved in subsequent combat. That is, the First World War ended before they had either completed supplementary training in England or had moved into front-line positions.

Data collection processes were similar to a previously published study [7]. This method involved examination of digitalized and publicly available personal military files for the First World War military personnel from Archives New Zealand [8]. Any data that could not be obtained this way was searched for in the official Births, Deaths and Marriages (BDM) database for New Zealand [9] or other sources (e.g. the Cenotaph database held by Auckland Museum [10] and the website ancestry.com.au for genealogical records). As in the previous work, occupational class was determined by using an established historical classification system designed for New Zealand [11]. There were no data in the archives to help to distinguish between conscripts $v s$. volunteers, but the former probably dominated during 1918.

The main finding was that there was no statistically significant difference in the lifespan of the outbreak cohort and the comparison cohort from the contemporaneous troopships (means of 71.5 and 71.0 years, respectively; Table 1). Indeed, there were some suggestions that the outbreak cohort was slightly healthier in terms of being more likely to survive into the period from 1950 onwards $(P=0.036)$. They were also more likely to participate in military service again in the Second World War $(P=0.043)$, which meant passing a health screening process on entry to the military. Furthermore, they also seemed less likely to die in the year of the subsequent 1957 pandemic caused by a $\mathrm{H} 2 \mathrm{~N} 2$ strain (but this was not statistically significant). Collectively, these results are consistent with a possible healthy survivor effect for those in the outbreak cohort (i.e. less healthy individuals with underlying disease may have been more likely to die in the troopship outbreak). Certainly these results do not support any strong impact from differing risk of infection and severity of infection from pandemic influenza in 1918 in increasing long-term mortality, at least for these military populations.

Nevertheless, these results need to be considered in the context of the slight differences between the two cohorts. That is, more lifespan data were missing for the comparison cohort $(4 \cdot 6 \%$ vs. $2 \cdot 6 \%, P=0 \cdot 006)$ and this group was very slightly older in mid-1918 (27.8 vs. $27 \cdot 2$ years, $P=0 \cdot 028$, Table 1$)$. The comparison cohort also had a slightly poorer mean occupational class score $(6 \cdot 9 / 9 \mathrm{vs} .6 \cdot 7 / 9)$ but the latter was not statistically significant. Finally, the comparison cohort were also more likely to have an occupation that was classified as rural $(33 \cdot 3 \%$ vs. $27 \cdot 0 \%, P<$ $0 \cdot 001)$, although there was no statistically significant difference in lifespan by rural $v s$. non-rural occupation (71.8 vs. 71.0 years, respectively). 
Table 1. Comparison of the characteristics of the outbreak cohort with the comparison cohort (from two contemporaneous troopships) and the results for lifespan and mortality differences

\begin{tabular}{|c|c|c|c|c|c|}
\hline \multirow[b]{2}{*}{ Characteristic } & \multicolumn{2}{|c|}{ Outbreak cohort } & \multicolumn{2}{|c|}{ Comparison cohort } & \multirow[b]{2}{*}{$P$ value* } \\
\hline & $N$ & $\%$ or (S.D.) & $N$ & $\%$ or (S.D.) & \\
\hline Data quality and pandemic impact & $(N=1107)$ & & $(N=1108)$ & & \\
\hline Missing lifespan data (e.g. date of death not identified) & 29 & $2 \cdot 6 \%$ & 51 & $4 \cdot 6 \%$ & $0 \cdot 006$ \\
\hline Missing data on occupation & 2 & $0 \cdot 18 \%$ & 5 & $0 \cdot 45 \%$ & $0 \cdot 189$ \\
\hline Died of pandemic influenza in 1918-1919 & 77 & $7 \cdot 0 \%$ & 8 & $0 \cdot 72 \%$ & $<0 \cdot 00001$ \\
\hline $\begin{array}{l}\text { Results when excluding influenza pandemic deaths and } \\
\text { those with missing lifespan data }\end{array}$ & $(N=1001)$ & & $(N=1049) \dagger$ & & \\
\hline \multicolumn{6}{|l|}{ Age in mid-1918 (years) } \\
\hline Mean (S.D.) & $27 \cdot 2$ & $(6 \cdot 8)$ & $27 \cdot 8$ & $(7 \cdot 0)$ & $0 \cdot 028$ \\
\hline Median & $25 \cdot 3$ & & $27 \cdot 0$ & & - \\
\hline Interquartile range (IQR) & $20 \cdot 7-32 \cdot 5$ & & $20 \cdot 8-33 \cdot 2$ & & - \\
\hline Range & $18 \cdot 9-49 \cdot 3$ & & $16 \cdot 9-51 \cdot 1$ & & - \\
\hline \multicolumn{6}{|l|}{ Occupational class (nine levels) } \\
\hline Highest status, three classes (e.g. doctor) & 49 & $4 \cdot 9 \%$ & 52 & $5 \cdot 0 \%$ & $0 \cdot 045$ \\
\hline Middle three classes (e.g. postal officer) & 399 & $40 \cdot 0 \%$ & 363 & $34 \cdot 7 \%$ & \\
\hline Lowest three classes (e.g. labourer) & 551 & $55 \cdot 2 \%$ & 632 & $60 \cdot 4 \%$ & \\
\hline Mean occupational class score (s.D.) & $6 \cdot 7$ & $(2 \cdot 0)$ & $6 \cdot 9$ & $(2 \cdot 1)$ & $0 \cdot 204$ \\
\hline Median occupational class score & 7 & & 7 & & - \\
\hline IQR & $5-8$ & & $5-9$ & & - \\
\hline Rural occupation & 270 & $27 \cdot 0 \%$ & 349 & $33 \cdot 3 \%$ & $<0 \cdot 001$ \\
\hline \multicolumn{6}{|l|}{ Possible ethnicity } \\
\hline $\begin{array}{l}\text { Individual had any Māori (indigenous) name (first, } \\
\text { middle and surnames) }\end{array}$ & 2 & $0 \cdot 18 \%$ & 2 & $0 \cdot 19 \%$ & $0 \cdot 482$ \\
\hline \multicolumn{6}{|l|}{ Military service } \\
\hline $\begin{array}{l}\text { Mean years spent in military service (for those not } \\
\text { dying during active service) (s.D.) }\end{array}$ & $1 \cdot 6$ & $(0 \cdot 48)$ & $1 \cdot 5$ & $(0 \cdot 50)$ & $0 \cdot 050$ \\
\hline $\begin{array}{l}\text { Median discharge date from military service (for the } \\
\text { First World War) }\end{array}$ & 9/17/1919 & & $9 / 17 / 1919$ & & - \\
\hline $\begin{array}{l}\text { In NZ military forces in the Second World War } \\
\text { (1939-1945) out of those alive on } 1 \text { Jan. 1939\$ }\end{array}$ & 142 & $15 \cdot 3 \%$ & 132 & $12 \cdot 6 \%$ & $0 \cdot 043$ \\
\hline \multicolumn{6}{|l|}{ Lifespan and mortality results } \\
\hline Lifespan. mean years (s.D.) & $71 \cdot 5$ & $(13 \cdot 6)$ & $71 \cdot 0$ & $(14 \cdot 1)$ & $0 \cdot 501$ \\
\hline Lifespan, median years & $73 \cdot 0$ & & $72 \cdot 8$ & & - \\
\hline IQR & $64 \cdot 3-81 \cdot 2$ & & $63 \cdot 6-81 \cdot 4$ & & - \\
\hline Deaths in the period $1918-1929$ & 35 & $3 \cdot 5 \%$ & 45 & $4 \cdot 3 \%$ & $0 \cdot 179$ \\
\hline Deaths in the period $1930-1949$ & 138 & $13 \cdot 8 \%$ & 169 & $16 \cdot 1 \%$ & $0 \cdot 070$ \\
\hline Deaths in the period 1950 onwards & 828 & $82 \cdot 7 \%$ & 835 & $79 \cdot 6 \%$ & $0 \cdot 036$ \\
\hline $\begin{array}{l}\text { Died in the year of the } 1957 \text { influenza pandemic } \\
\text { (all causes)§ }\end{array}$ & 24 & $3 \cdot 6 \%$ & 34 & $5 \cdot 1 \%$ & $0 \cdot 088$ \\
\hline As above but for 1957 and $1958 \S$ & 46 & $6 \cdot 8 \%$ & 59 & $8 \cdot 8 \%$ & $0 \cdot 089$ \\
\hline
\end{tabular}

* All analyses conducted in Epi Info v. 7.1.3.0 (CDC, USA) using $\chi^{2}$ tests, ANOVA and the Mann-Whitney/Wilcoxon two-sample test (when ANOVA was not appropriate due to variances not being homogeneous).

$\dagger$ Comprised of 541 men on the troopship Athenic and 508 men on the troopship Ulimaroa.

$\$$ Many were stationed in New Zealand during the Second World War and not in conflict zones (hence only one was killed). $\S$ The denominators for these calculations were those alive on 1 January 1957 ( $n=676$ for the outbreak cohort and $n=672$ for the comparison cohort).

Furthermore, the results from this study may have limited generalizability to the wider population. That is because all these personnel were subject to the healthy soldier effect [12] (a selection effect analogous to the healthy worker effect). Indeed, the rejection rate for new military recruits was relatively high for the November 1916 to November 1918 period in New Zealand at $57 \cdot 6 \%(n=77900$ rejected out of 
$n=135282$ examined) [13]. In addition, by selecting military personnel that left New Zealand, rather than performing military duties back in the home country, there was probably also a 'healthy warrior effect' operating [14].

In a separate analysis we considered deaths from pandemic influenza itself. In the outbreak cohort there were 77 pandemic-related deaths associated with the outbreak on the Tahiti in September/ October 1918 with no deaths in these months in the comparison cohort from the two contemporaneous troopships (Table 1). But then for the period from mid-October 1918 to the end of 1919 there were no pandemic-related deaths in the outbreak cohort $v s$. eight such deaths in the comparison cohort $(P=$ 0.0023 , with all these deaths being in November/ December 1918 except for one in 1919, Table 1). A plausible explanation for this difference is that the outbreak cohort may have been immunized against further infection in the subsequent pandemic waves.

In conclusion, this study found no evidence that exposure to a severe outbreak of pandemic influenza on a troopship in 1918 reduced the lifespan of the survivors compared to military personnel on two contemporaneous troopships. However, these results were for relatively healthy young male populations of military personnel and so may not be generalizable to other populations.

\section{ACKNOWLEDGEMENTS}

The authors thank Professor Dennis Shanks (Australian Army Malaria Institute, Brisbane, Australia) for providing helpful comments on the manuscript.

\section{DECLARATION OF INTEREST}

None.

\section{REFERENCES}

1. Mamelund SE. Effects of the Spanish influenza pandemic of 1918-19 on later life mortality of Norwegian cohorts born about 1900. Oslo: Department of Economics, University of Oslo; 2003.

2. Azambuja M. Spanish flu and early 20th-century expansion of a coronary heart disease-prone subpopulation. Texas Heart Institute Journal 2004; 31: 14-21.

3. Cardenas G, et al. Neurological events related to influenza $\mathrm{A}(\mathrm{H} 1 \mathrm{~N} 1)$ pdm09. Influenza and Other Respiratory Viruses 2014; 8: 339-346.

4. Tappe D, Alquezar-Planas D. Medical and molecular perspectives into a forgotten epidemic: encephalitis lethargica, viruses, and high-throughput sequencing. Journal of Clinical Virology 2014; 61: 189-195.

5. Summers JA, et al. Mortality risk factors for pandemic influenza on New Zealand troop ship, 1918. Emerging Infectious Diseases 2010; 16: 1931-1937.

6. Summers JA, et al:: Severe impact of the 1918-19 pandemic influenza in a national military force. New Zealand Medical Journal 2013; 126: 36-47.

7. Wilson N, et al:: Mortality of first world war military personnel: comparison of two military cohorts. British Medical Journal 2014; 349: g7168.

8. New Zealand Government. Archway. Archives New Zealand (www.archway.archives.govt.nz).

9. Births Deaths and Marriages Historical Records. (http:// bdmhistoricalrecords.identityservices.govt.nz/Home/).

10. Auckland War Memorial Museum. Cenotaph database (http://muse.aucklandmuseum.com/databases/Cenotaph/ locations.aspx?).

11. Olssen E, Hickey M. Class and Occupation: The New Zealand Reality. Dunedin: Otago University Press, 2005.

12. McLaughlin R, Nielsen L, Waller M. An evaluation of the effect of military service on mortality: quantifying the healthy soldier effect. Annals of Epidemiology 2008; 18: 928-936.

13. Editorial. Territorial military training and physical efficiency. New Zealand Medical Journal 1920; 19: 245-246.

14. Wilson J, et al. Is previous psychological health associated with the likelihood of Iraq War deployment? An investigation of the 'healthy warrior effect'. American Journal of Epidemiology 2009; 169: 13621369. 